\title{
ADULT EDUCATION TEACHER'S PERCEPTION OF GAMIFICATION IMPLEMENTED IN DISTANCE EDUCATION
}

\author{
F.G. Gunnars ${ }^{1}$, A.P. Palmquist ${ }^{2}$, M. Sundgren ${ }^{1}$ \\ ${ }^{1}$ Department of Education, Mid Sweden University (SWEDEN) \\ ${ }^{2}$ Department of Applied IT, University of Gothenburg (SWEDEN)
}

\begin{abstract}
This paper discusses perceptions of educational gamification and its potential opportunities for reducing student dropout and teacher workload. Interviews of nine teachers and their technology acceptance were studied in conjunction with the implementation of a gamified online system during 2019, fully designed for distance education. Results indicate perceptions of reduced workload, prevention of students from handing in late, and facilitating activity in courses. However, perceptions of clear suspicion towards Educational Gamification also related acceptance as insufficient for behavioral intent until very conclusive result demonstrations of behavioral performance are available to the teachers. Implications for lifelong learning and ethical concerns are briefly discussed.
\end{abstract}

Keywords: Adult Education, Distance Education, Gamification, Teacher adoption.

\section{INTRODUCTION}

The nature of employment is currently undergoing a digitalization and automation transformation that entails a workforce re-skilling demand for higher flexibility [1]-[4]. The rapid change of skills combined with the size of the workforce renders traditional onsite courses unmanageable, suggesting demand for distance education [5], [6]. Further, the flexible format reconfigurations of 2020 brought distance education into focus [7].

Common challenges with distance education are low completion and high dropout [8], [9]. The lack of a fixed classroom makes it harder for teachers to address inclusive aspects in education [10]. Educational Gamification (EG) may provide a piece of the puzzle to this issue, by using flexible and dynamic game elements similar to step-by-step formative assessment principles that have proven effective for student motivation, engagement, and retention in distance education and online learning [11]-[13]. However, the novel field of EG has overlooked areas despite this efficacy [14]. For example, studies have shown results of teacher's acceptance and behavioral intent ranging from high acceptance [15], [16], low behavioral intent [17] and, mixed results [18].

In this study, in-service teachers were interviewed in conjunction with a government-funded project that took place in 2019. The project concerned the implementation of gamification fully designed for distance education where the teachers work. Given the projects' EG implementation aspect, the presented paper emphasizes teachers' acceptance of usefulness to a higher degree than capability, effort or social factors.

RQ1: What changes in teachers' perception on EG can be identified in pre- and post interviews in conjunction with the implementation of a gamified system?

RQ2: How does the perception of student dropout and teacher workload after experiencing the implementation of a gamified system relate to acceptance and behavioral intent towards EG?

The results outline teachers' technology acceptance and can be viewed as relevant for different stakeholders such as educational technology providers, school leaders, and scholars. Further particular interest may concern holistic flexible lifelong learning opportunities in relation to educational format reconfigurations of 2020 .

\subsection{Background}

The presented study is part of an innovation project intending to investigate the usefulness implementing gamification into diverse Learning Management Systems (LMSs). One of the project's primary goals was to examine if gamification could decrease the dropout rate and increase the completion rate in adolescence, adult, and higher education courses. It is an in house developed and co-designed platform owned by the educational provider. The educational providers, developers, 
teachers, students and developers have contributed to the design, to provide usability and ease of use for the different stakeholders in the platform. The LMS interface design is inspired by multimodal communication to increase accessibility for the highly diverse students' groups (Fig. 1).

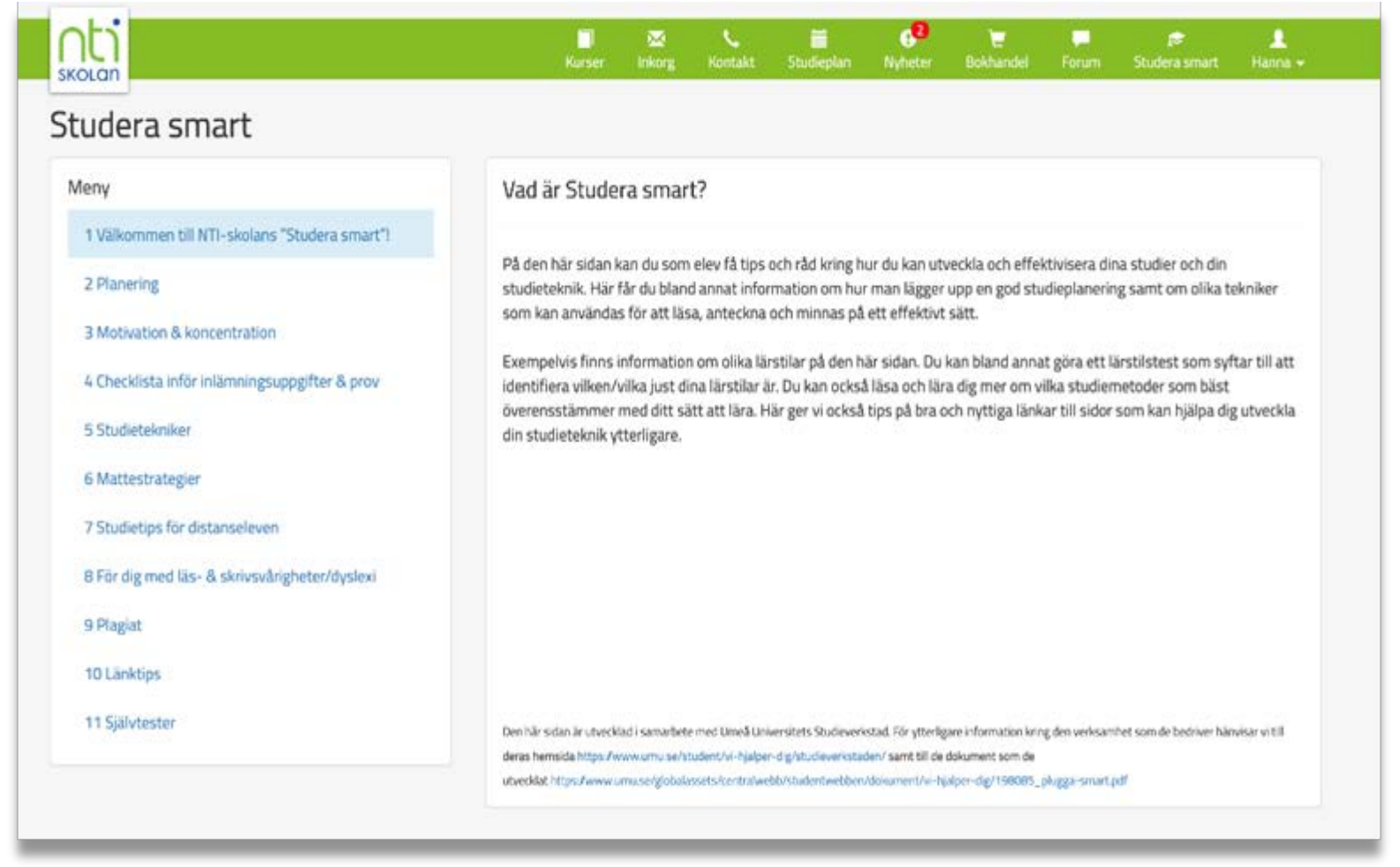

Figure 1 The LMS Interface before the implementation.

In general, educational providers in Sweden may operate solely as a distance course provider for various municipalities and serves approximately 35000 adult students with different courses each year. The educational provider in this study gives around 300 different online courses and programs up to the upper secondary education tier. The courses stretch over different timespans. The shortest courses stretch for three weeks, and the lengthiest programs are between three to five years. The students can choose from three different study-paces: $100 \%, 50 \%$, and $25 \% .100 \%$ is called full-time and requires a time commitment equal to a 40-hour workweek. Dissimilar from the often-automated massive open online courses (MOOC), the learning with the LMS is highly teacher-driven and more akin to a fixed classroom. Lectures held by the teachers ran several times a day, and the adult learners were expected to study with the LMS where at least one teacher was present for student support during the entire workday. Teaching material (e.g., presentations, video lectures, articles) was available in the LMS at all times.

The gamification implementation was integrated into the LMS interface (Fig. 2) and would include the following game elements: mission, achievement, level and a progression bar. To gain levels, students had to complete specific missions, and when a series of missions were completed, they would attain an achievement token. The student's level was shown in the top left-hand corner, and when pressing on the level icon, the experience points needed for reaching the next level were shown. 


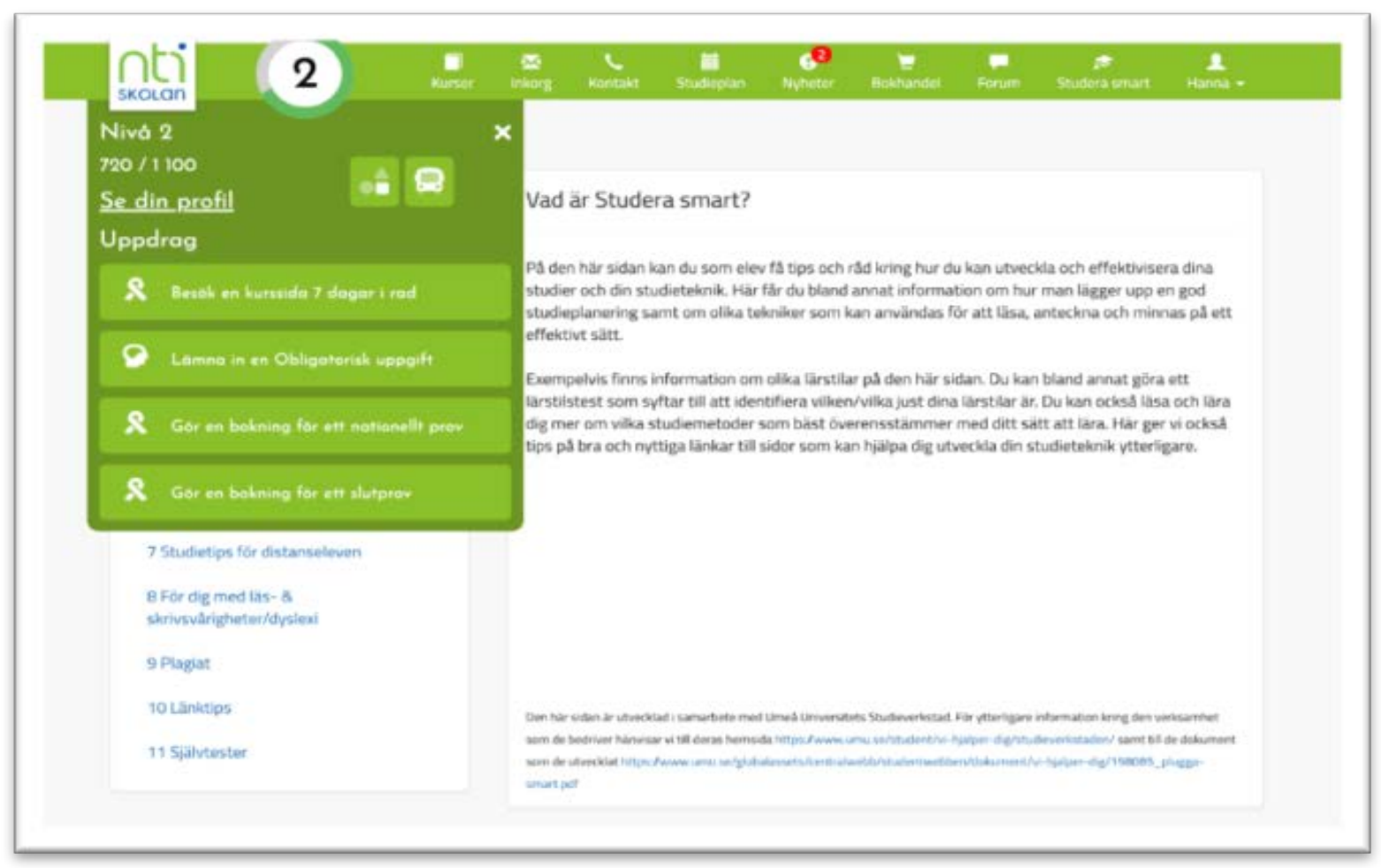

Figure 2 LMS Interface after the implementation (gamification curtain opened)

\section{METHODOLOGY}

This paper takes a qualitative inductive approach towards analysis of interviews with nine teachers, for the study of teachers' perceptions concerning the implementation of a gamified online system fully designed for distance education.

\subsection{Participants}

A serial semi-structured interview approach was taken to provide flexibility and more deeply inquire complex issues of the teachers' expressed perception and change over time [19]. The teachers participated in two semi-connected interview sessions, one at the beginning of the implementation and one after two months. The teacher interviews were conducted online and lasted 20-30 minutes per session and were recorded after getting verbal consent from the teachers. The interviews included questions relating to the teachers' expectations with the implementation, their gamification experience in the classroom, and its effect on their work and students.

Table 1. Respondents.

\begin{tabular}{|c|c|c|c|c|c|c|}
\hline Name & Age & $\begin{array}{l}\text { Teaching } \\
\text { subject }\end{array}$ & $\begin{array}{c}\text { Playing Video Games for } \\
\text { leisure }\end{array}$ & $\begin{array}{c}\text { Experience } \\
\text { with EG }\end{array}$ & $\begin{array}{c}\text { Took part in } \\
\text { session } 1\end{array}$ & $\begin{array}{c}\text { Took part in } \\
\text { session } 2\end{array}$ \\
\hline Teacher $1(\mathrm{~T} 1)$ & 29 & English & Sometimes & None & Yes & Yes \\
\hline Teacher 2 (T2) & 29 & English & Sometimes & None & Yes & Yes \\
\hline Teacher 3 (T3) & 25 & English, History & Never & Low & Yes & Yes \\
\hline Teacher 4 (T4) & 32 & English & Frequently & None & Yes & Yes \\
\hline Teacher 5 (T5) & 37 & History, Swedish & Rarely & Low & Yes & No \\
\hline Teacher 6 (T6) & 26 & History, Civics & Never (but used to frequently) & None & Yes & Yes \\
\hline Teacher 7 (T7) & 33 & Math & $\begin{array}{l}\text { Occasionally (but used to } \\
\text { frequently) }\end{array}$ & None & Yes & No \\
\hline Teacher 8 (T8) & 37 & Math & Sometimes & Low & Yes & No \\
\hline Teacher $9(\mathrm{~T} 9)$ & 36 & Math & Sometimes & None & Yes & Yes \\
\hline
\end{tabular}




\subsection{Data collection}

In a pre-post implementation study, the second author interviewed ten adult education teachers' perceptions one month before and one month after the EG implementation. The interview sessions were conducted through Zoom due to geographical distance, and the data collection was conducted in two stages. Overall, the first interview session yielded approximately 85 minutes of audio-recorded materials, the second session 136 minutes, which constitutes 221 minutes of self-reported data. Two interviews had to be omitted due to a problem with the recording, excluding one of the participating teachers from analysis. After the interviews were finished, the recordings were transcribed and translated verbatim by the first author, in part ensuring increased credibility in regards to investigator confirmation bias [20].

\subsection{Data analysis}

The Interview transcripts were analyzed qualitatively through a thematic analysis procedure in two cycles [21]. The first cycle was an open, descriptive coding procedure where the first author identified meaningful utterances in the transcripts [22]. In the second cycle, the first author identified categories and themes using pattern coding, which then were verified by the second and third author for reliability check [20], [22]. The codes were informed by the taxonomy of factors affecting attitudes towards educational and digital technologies, as outlined by Kemp et al. [23] in a qualitative review of the most influential and theorized factors of several acceptance models. The taxonomy was deemed relevant due to its broad applicable fit, specific educational technology focus and parsimonious groupings of complex phenomena.

\section{RESULTS}

Key findings are presented below, where all quotes systematically are referring to expressions by different teachers in the interview transcripts, such as (T3) representing teacher 3 (Table 1). Overall, findings show that teachers' perceptions changed during implementation, which primarily related the taxonomy groupings social factors and attitude and affect that describes others' opinions on the use of educational technology and associated affectual states [23]. Further, suspicion in regards to job-fit, which relates the value of using educational technology in their work, was expressed along the secondary taxonomy grouping system and learning usefulness which relates systemic factors that affect the ability to use educational technology, and directly related to the measurement construct results demonstrability from a separate taxonomy group [23]. Student key performance indicators is also discussed along the tertiary taxonomy group facilitating conditions, which is part of the taxonomies perceived behavioral control and situational concerns [23]. For further relations between themes and secondary taxonomy groupings, see Table 2.

Table 2. Identified categories and themes as informed by the final taxonomy by Kemp et. al [23, pp. 2408-09].

\begin{tabular}{l|l}
\hline \hline \multicolumn{1}{c|}{ Theme } & \multicolumn{1}{c}{ Secondary Taxonomy Group } \\
\hline $\begin{array}{l}\text { Initial suspicion towards "the game } \\
\text { part" changed }\end{array}$ & Attitude, Affect, Social Influence, System and Learning Usefulness \\
\hline $\begin{array}{l}\text { High expectations of the } \\
\text { demonstrability of performance results }\end{array}$ & $\begin{array}{l}\text { Intrinsic Motivation, System and Learning Usefulness, Visibility, } \\
\text { Feedback, Playfulness }\end{array}$ \\
\hline $\begin{array}{l}\text { School key performance indicator for } \\
\text { facilitating conditions }\end{array}$ & $\begin{array}{l}\text { Intrinsic Motivation, System and Learning Usefulness, Visibility, } \\
\text { Feedback, Environmental \& Situational, System Function \& Response }\end{array}$ \\
\hline $\begin{array}{l}\text { Adapting the classroom to } \\
\text { technological developments }\end{array}$ & Environmental \& Situational, Absorption, Information Security \& Privacy \\
\hline
\end{tabular}

\subsection{Initial suspicion towards "the game part" changed}

Initially, some perceptions indicated suspicion towards the implementation due to general acknowledgments of others' negative opinions of EG. For example, opinions concerned "the relatively unfamiliar nature of the concept often leads oneself getting stuck in the game part" (T3) which often had elements of "overly visual and flashy graphics" (T6) which were easy to associate as unnecessary, and childish. This was also perceived as a risk for increased requirement of excessive technical skills. They were anxious that resources would be wasted due to the perception that EG 
mostly benefits children. Further, they were anxious that their workload would increase because of efforts to learn the new technology, and "acting as technical support" (T9) for their adult student groups, presumed unfamiliar to games.

However, in the post-interviews, teachers' notions clearly indicated acceptance towards the implementation. Contrary to these initial suspicions, the implementation had at times made their work less arduous preventing students from handing in late, motivating them, and facilitating activity in the courses. Some teachers also expressed a relief about "that the implementation have not impeded any of my work, at all. I haven't even noticed that it's there at all, to be honest" (T6) and was also "surprised at how fast it went" (T1), and had stopped being concerned about wasted resources in the implementation stage.

\subsection{High expectations of the demonstrability of performance results}

Despite reaching a high level of acceptance and perceived value of the usefulness of EG, most teachers expressed a high expectation of result demonstrability before committing to behavioral intent towards using EG and the associated affectual state in their work. The perceived value was primarily expressed according to basic Pavlovian method "through stimuli providing a sensation of reward" (T9), but also as making the learning for their students "more inviting, accessible, inclusive and fun" (T3). Such aspects were mostly acknowledged to provide lasting motivation, engagement, and retention in their courses.

Arguably, this acknowledgment of motivational benefits for students would indicate EG as reasonable, well-founded, and implementable with low effort, but this was rarely expressed. Even in conjunction with a "seamless" (T9) and "unintrusive" (T6) implementation of well-founded EG, most teachers seemed suspicions towards behavioral intent until "there is a well-founded basis to stand upon currently there is no ground to stand upon at all. I don't know, with this being such a new thing, there's nothing to point to as to say, this is how it works" (T1). With this suspicion also relating perceptions of EG as too novel or experimental to trust, very conclusive result demonstrations of behavioral performance need to be more readily available to them. Some teachers hesitated to even express their intuitive feeling towards the implementation until "we see the results after a couple of months" (T5). Some viewed their attitude and affect toward EG as "not valuable to anyone. Yes, I would strongly like to emphasize that it is completely meaningless" (T4) without such behavioral data. Whether correct or not, seeing "the semantics of gamification irrelevant ... it is solely the result that is the most exciting part" (T1) of the implementation indicates result demonstrability as of overwhelmingly high importance.

\subsection{School key performance indicator for facilitating conditions}

Student motivation, engagement, and retention are especially important aspects of distance education. Before implementation, well-established "fixed structures" (T4) in the courses were already in place to support motivational aspects, such as "an email schedule and rigorous reading scaffolding tasks" (T7). Some of these structures already had EG characteristics before implementation (e.g. "assessment tasks that are dynamically unlocked based upon study pace" (T1)).

While a few of the respondents made a connection and optimistically stated that EG "maybe work well on distance education" (T4), most of them perceived EG as "difficult to implement, you know... there's just not that many ways to do it" (T1) both in terms of effort and job-fit. This may be related to the facilitating conditions of their administration, which currently are adapted to a "student key performance indicator calculated based upon risk-assessment of dropouts" (T6). In short, the key performance indicator predicts a certain amount of student dropouts, and conditions are adjusted to "how many realistically could be handled" (T9). If this key performance indicator suddenly were to change, it would require systemic changes, which may require "very substantial" (T1) results demonstrability to justify the perceived short-term effort and financial cost.

\subsection{Adapting the classroom to technological developments}

A general sense of optimism also seemed to rely on the "importance of keeping ourselves at the forefront" (T3) of technological developments. Since the younger generation grew up with technology, the teachers expect technology integration as "it's something they grew up with in a completely different way" (T1). This renders alternatives such as books for certain tasks as "a struggle" (T2) in contrast. These concerns were viewed as likely to result in systemic changes. There was some anxiety about further consequences of potential systemic changes, such as increased data collection 
possibilities. These possibilities raise the issues of protecting the integrity of students and other dehumanizing concerns such as "reducing the learning of the students to ones and zeroes" (T1), but this did not ultimately affect their optimism.

\section{CONCLUSIONS}

Findings are discussed and summarized below in direct relation to the two RQs of this paper. Suggestions for further research are presented based on the implications.

\subsection{Implications of changed teacher perception of EG for adult education}

The first $R Q$ of this paper concerned the changes in teachers' perception on EG that can be identified in pre- and post interviews in conjunction with the implementation of a gamified system. A key finding that relates this question is that the teacher's perceptions of gamification seem to have changed over time, to view it from initial suspicions of childish and unnecessarily technical to more serious and beneficial for adult students and their learning. Low behavioral intent and mixed results of teachers' perceptions concerning the implementation of gamification for adult education, as seen in [17], [18], was confirmed by this study. It appears that time spent with the EG implemented in the teachers' work forms a familiarization for the teachers: this is not uncommon with other models investigating technology acceptance [23].

Previous studies on teachers' perceptions of gamification (e.g. [15], [16], [18]) simply perform one session for collecting data on teachers' perceptions. The results indicate that gamification might need a start-up phase, and attitude toward gamification might change once it is understood, indicating that research with several sessions over time is crucial.

\subsection{Implications of low behavioral intent towards EG in adult distance education}

The second $R Q$ of this paper concerned the acceptance and behavioral intent towards $E G$ after experiencing the implementation of a gamified system in relation to their perception of student dropout and teacher workload. A clear change in adult education teachers' acceptance of EG after perceiving and acknowledging the usefulness of the implementation in their distance education work was not enough for them committing to behavioral intent towards using EG and the associated affectual state. For example, initial suspicions of increased workload were quickly disproved, and student retention were perceived to improve slightly. Yet, clear demonstrations of behavioral performance results were also demanded, possibly due to systemic facilitating conditions.

As flexible format reconfigurations of 2020 often have brought distance education into focus to the extent that it is a requirement [7], research about distance education that was conducted prior to this year seem to consist of a particular interest of voluntary aspect, as it may have not been required to the same extent yet it was still conducted. Further, as educational digitalization and automation transformation has brought stronger demand [1]-[6], it seems highly relevant to highlight previous research about the efficacy of EG (e.g. [11], [12], [14]) as contrast to the forced reconfigurations.

The presented study as analyzed from ground up in 2021 indicates that:

a) There seem to be a discrepancy regarding teachers' conceptualization of EG in part due to facilitating conditions of 2019.

b) High acceptance, capability, effort and acknowledgement do not guarantee optimistic affect and attitudes towards behavioral intent.

c) There is an urgent need to investigate teachers' acceptance and adoption of EG in direct relation to behavioral complementary factors, to provide a more holistic understanding of flexible lifelong learning opportunities.

\section{ACKNOWLEDGEMENTS}

This study was partly supported by the Swedish innovation agency Vinnova (grants number 201802953. 


\section{REFERENCES}

[1] C. A. Chiţiba, "Lifelong learning challenges and opportunities for traditional universities," Procediasocial and behavioral sciences, vol. 46, pp. 1943-1947, 2012.

[2] S. C. Conceição, "Competing in the world's global education and technology arenas," New Directions for Adult and Continuing Education, vol. 2016, no. 149, pp. 53-61, 2016.

[3] S. Kasriel, "Skill, re-skill and re-skill again. How to keep up with the future of work," in World Economic Forum, 2017, vol. $31 . \quad$ [Online]. Available: https://www.weforum.org/agenda/2017/07/skill-reskill-prepare-for-future-of-work/

[4] J. Y. Kim, Ed., World development report 2019: The changing nature of work. The World Bank Group, 2019. [Online]. Available: https://www.worldbank.org/en/publication/wdr2019

[5] J. Dockter, "The problem of teaching presence in transactional theories of distance education," Computers and Composition, vol. 40, pp. 73-86, 2016.

[6] World Economic Forum, "Towards a reskilling revolution: A future of jobs for all," Davos, 2018. [Online]. Available: http://hdl.voced.edu.au/10707/448194

[7] R. T. Nørgård, "Theorising hybrid lifelong learning," British Journal of Educational Technology, vol. 52, no. 4, pp. 1-15, 2021.

[8] S. S. Christensen and J. S. Spackman, "Dropout Rates, Student Momentum, and Course Walls: A New Tool for Distance Education Designers.," Journal of Educators Online, vol. 14, no. 2, 2017.

[9] D. F. Onah, J. Sinclair, and R. Boyatt, "Dropout rates of massive open online courses: behavioural patterns," in EDULEARN14 proceedings, 2014, vol. 1, pp. 5825-5834.

[10] A. Tesolin and A. Tsinakos, "Opening real doors: Strategies for using mobile augmented reality to create inclusive distance education for learners with different-abilities," in Mobile and Ubiquitous Learning: An International Handbook, Y. Shengquan, A. Mohamed, and T. Avgoustos, Eds. Cham: Springer, 2018, pp. 59-80. [Online]. Available: 10.1007/978-981-10-6144-8

[11] A. Antonaci, R. Klemke, and M. Specht, "The effects of gamification in online learning environments: A systematic literature review," Informatics, vol. 6, no. 3, p. 32, 2019.

[12] J. Looyestyn, J. Kernot, K. Boshoff, J. Ryan, S. Edney, and C. Maher, "Does gamification increase engagement with online programs? A systematic review," PloS one, vol. 12, no. 3: e0173403, 2017.

[13] J. Koivisto and J. Hamari, "The rise of motivational information systems: A review of gamification research," International Journal of Information Management, vol. 45, pp. 191-210, 2019.

[14] C. Dichev and D. Dicheva, "Gamifying education: what is known, what is believed and what remains uncertain: a critical review," International journal of educational technology in higher education, vol. 14, no. 1, pp. 1-36, 2017.

[15] D. Alabbasi, "Exploring Teachers' Perspectives towards Using Gamification Techniques in Online Learning.," Turkish Online Journal of Educational Technology-TOJET, vol. 17, no. 2, pp. 34-45, 2018.

[16] J. Martí-Parreño, D. Seguí-Mas, and E. Seguí-Mas, "Teachers' attitude towards and actual use of gamification," Procedia-Social and Behavioral Sciences, vol. 228, pp. 682-688, 2016.

[17] F. Almeida and J. Simoes, "The role of serious games, gamification and Industry 4.0 tools in the Education 4.0 paradigm," Contemporary Educational Technology, vol. 10, no. 2, pp. 120-136, 2019.

[18] A. Palmquist, "'Gamification was not the problem' A case study exploring factors affect teachers approvement of gamification," in Academic Mindtrek '21: Proceedings of the 24th International Conference on Academic Mindtrek 2021, 2021, pp. 106-116.

[19] B. L. Read, "Serial interviews: When and why to talk to someone more than once," International Journal of Qualitative Methods, vol. 17, no. 1, pp. 1-10, 2018.

[20] A. K. Shenton, "Strategies for ensuring trustworthiness in qualitative research projects," Education for information, vol. 22, no. 2, pp. 63-75, 2004. 
[21] V. Braun and V. Clarke, "Using thematic analysis in psychology," Qualitative research in psychology, vol. 3, no. 2, pp. 77-101, 2006.

[22] A. M. Huberman and J. S. M. B. Miles, Qualitative data analysis: A methods sourcebook, 4th ed. Thousand Oaks, CA: Sage, 2019.

[23] A. Kemp, E. Palmer, and P. Strelan, "A taxonomy of factors affecting attitudes towards educational technologies for use with technology acceptance models," British Journal of Educational Technology, vol. 50, no. 5, pp. 2394-2413, 2019. 